\title{
ENGLISH TEACHER'” CULTURAL BACKGROUND AND THEIR TEACHING BELIEF
}

\author{
Heidy Wulandari \\ Sekolah Tinggi Keguruan dan Ilmu Pendidikan Soe \\ heidywulandari0@gmail.com \\ Soe, NTT, Indonesia
}

\begin{abstract}
This paper is a non-research article which aims at elaborating the relation between teachers' cultural background and their teaching beliefs. Way of thinking, behaviour, value, tradition, and belief in a society are taken into account as aspects of cultural background in this paper. Meanwhile belief is considered as unchangeable principle set in teachers' personality which has impact on what they do in the classroom. The red line between cultural background and teachers' beliefs has positive and negative side. Thus it is important for teachers to rely not only on their belief but also students' needs and other supporting teaching aspects in order to reach a successful teaching and learning process.
\end{abstract}

Key words: Cultural background, Teachers' belief

\section{INTRODUCTION}

In language teaching, teachers play important role as practitioner. Even though there is national standard curriculum, which leads to the supposed to be - similar language teaching practice in a nation, teachers as the decision maker determine how the curriculum is implemented in the class.

As the core actor of language teaching, teachers' decision on what to do in the classroom, how to face the classroom challenges, how to deal with the students, depends on their belief (Gilakjani and Sabouri, 2017). Hence, English teaching might be implemented in various ways. Taken as example English teachers in an advanced area let their students be creative and independent in learning. They guide the students to realize their errors and to find out the wayout to fix them themselves. The teachers are not worried to let the students be independent because they are accustomed to be independent with advanced facilities around them. It is different from English teachers in conventional area. They become the center of teaching and learning activity. They force the students to memorize vocabulary. They fix the students' problem and let the students imitating, not creating.

"Teachers are more inclined to regard students as active participants in the process of acquiring knowledge than to see the teachers' main role as the transmission of information and demonstration of "correct solutions". This is most true in northwest Europe, Scandinavia, Australia and Korea and least true in southern Europe, Brazil and Malaysia where teachers fall between the two views" (TALIS 2019, p. 4).

It can be seen that teachers in different countries have different beliefs about classroom practice. When in several countries students are supposed by the teachers to be active participants, other countries teachers belief that teachers are the problem solver of every problem in the classroom. The variety in the way English teachers teach is basically formed by the various belief of teaching. Gilakjani and Sabouri (2017) mentioned that teachers' belief is formed by their experience as learners and as teachers, their personality, and their education-based or researchbased principles. It can be said that all aspects mentioned by Gilakjani and Sabouri (2017) are covered in one term, that is cultural background.

As individuals in a society, teachers' personality is formed by the culture he live in. Besides, the experience and education they get are results of being involved in a society. Xu (2012) states that "teacher's belief is resulted from the teacher's selfinstruction, which is accumulated from social history and culture, personal experience and education, the teacher's teaching ability and students, etc". As added by Gilakjani and Sabouri (2017) teachers' beliefs identify their real behavior 
towards their learners. In other words, teachers' cultural background influences their teaching belief. Tedick (2005) argues that teachers' judgment is formed by socialisation and culturation. Hence, this paper is aimed at elaborating the red line between teachers' cultural background and their belief in teaching and learning.

\section{DISCUSSION \\ A. English Teacher Cultural Background}

Ornstein et al. (2011, p. 305) maintain that 'culture is a way of thinking and behaving; it's a group of traditions, memories, and written records, it shares rules and ideas, it accumulates beliefs, habits, and values. Therefore, as part of society who represents the culture of the society, teachers must be representing these aspects during their teaching and learning activities. Ha (2008) states that human being's activities reflect characteristics of a national culture. Considering Ornstein's aspects of culture, this paper discusses teachers' cultural background in five aspects consisting of way of thinking, behaviour, value, tradition, and belief in a society.

The first aspect of teachers' cultural background to be discussed is way of thinking. Different culture results different way of thinking. Therefore, teachers as one of culture representations must be having their own way of thinking which reflect their culture. Taken as example, English teachers in a globalized area must be thinking about the use of English as a global language. Therefore, they must be forcing their students to master the language for competing in the global era. In comparison, in villages, English function as global language is not very necessary because most of the students will become farmer after they graduate from school. Here the teachers only focus on grammar and memorizing words so the students are not prepared in their ability for using the language.

The second aspect of is behaviour. Different cultures may lead to different behaviour which then affects to different relation between teachers and students. Braine (2010, p.18) points out the different behaviour between native-speaker-Englishteachers (NS) and non-native-speakerEnglish teachers (NNS) in teaching nonnative-speaker-students based on his research on teachers' perspectives. According to Braine, NS is more original in using the language to teach while NNS have more empathy and more ability to understand the students' difficulty in teaching and learning process since they share the same linguistic cultural and educational background.

The third aspect of cultural background is value. Teachers as the representation of culture absolutely represent the value of the culture. The way teachers consider something is correct or incorrect, acceptable or unacceptable, important or unimportant, can be the way they represent their culture. For instance urban teachers view laptop as important thing in studying while rural teachers view laptop as a disturbing thing. In urban area where laptop is owned by most of the people, teachers allow students to bring their laptop to class for reason of teaching and learning process. It is different from the rural area where laptop is still rare and not all people there use it in working. There, teachers do not allow students to bring the laptop because they think that the students will pay more attention on the laptop than the teachers and they also do not want to take risk of being responsible if the laptop is stolen.

The fourth aspect to take into account is tradition. Kisaka (2015) conducted a study on how cultural factors hinder students' English mastery and one of the factors is the language used in traditional ceremony. In ceremonies like weddings, funerals, and circumcitions, the community uses purely mother tongue. If in a week there are three traditional ceremonies then the intensity of using mother tongue is greater than using English. Taking a red line, teachers and students who attend the ceremony may get accustomed of using mother tongue more intensive than using English so it can be that in the class teachers will use mother tongue to translate to English because the students can only understand mother tongue. 
The fifth aspect is belief. As mentioned before, belief itself is one of cultural background aspects. Therefore it is clear that cultural background is the root of teachers' teaching belief. TALIS (2009) mentioned about the various preference of beliefs upon constructivist belief and Direct transmission beliefs among countries as seen in the picture below.

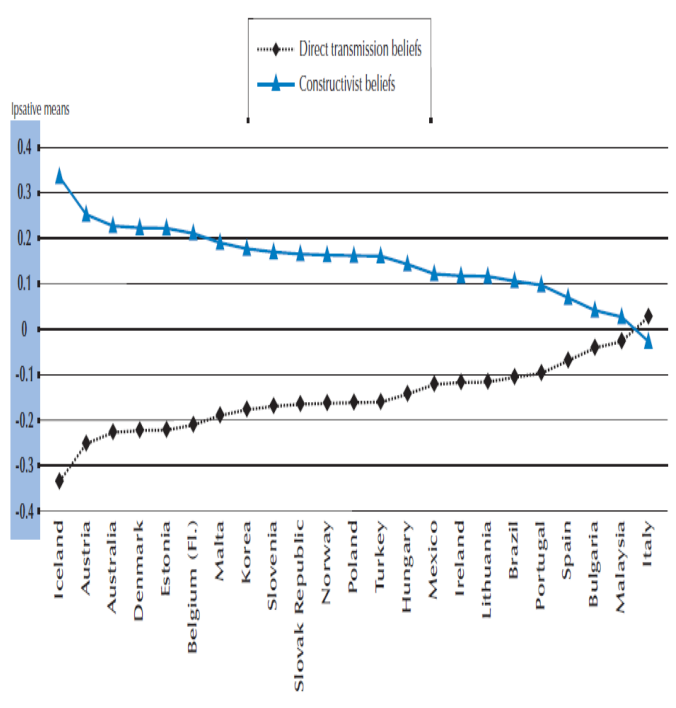

Figure 1. Country profiles of beliefs about the nature of teaching and learning (OECD, TALIS Database, 2009)

Figure 1 shows that in most countries other than Italy, teachers believe in constructivist view. In this case they believe that students are the center of teaching and learning process. However in detail, each country has different strength of preference. The preference for a constructivist view is stronger in Iceland, Australia, Korea, northwestern Europe and Scandinavia than in Malaysia. This proves that cultural background of teachers in different countries brings different beliefs of teaching and learning process.

\section{B. English Teacher's Belief}

Teachers' belief which is also called teachers' philosophy means the relation between teachers and the subject matter which is represented by the way teachers view and value the subject matter. Green and Mcntyre (2011, p.22) cite that 'teachers' belief about the subject matter considers how teachers assume and value the subject matter personally'.
Therefore, English teachers' belief means the way English teachers view and value English as their subject matter of teaching. The belief deals with the goal in teaching English and the way to reach the goal. Green and Mcntyre (2011, p.13) explain that personal philosophy of teaching is set by thinking firstly about what to achieve in the teaching and learning process. Then they provide the steps of thinking about the way to reach the goal which consists of how to value different component parts in English and how they relate, what is interesting, difficult and less comfortable in English to teach, and what to learn by the students during the teaching and learning process of English.

In planning the lessons, adopting types of decisions, and in classroom practice, teachers' belief has greater influence than teacher knowledge (Xu, 2012; Gilakjani and Sabouri 2017). It means that belief is not merely knowledge or something in the teachers' mind. Acikalin (2009) distinguishes beliefs and knowledge according to their typical characteristics.

"Beliefs refer to suppositions, commitments, and ideologies while knowledge refers to factual propositions and the understandings that inform skillful action. Beliefs do not require a truth condition while knowledge must satisfy "truth condition". Beliefs is based on evaluation judgment while knowledge is based on objective fact. Beliefs cannot be evaluated while knowledge can be evaluated or judged. Beliefs is episodicallystored material influenced by personal experiences or cultural and institutional sources while knowledge is stored in semantic networks. Beliefs is static while knowledge often changes." (Acikalin 2009, p. 4)

Hence, teachers' belief is a form of core typical principle which has been formed inside the teachers and influences not only the teachers' mind but also their behaviour. It grows inside the teachers' personality, and cannot be easily manipulated. 
Experts categorizes teacher's belief in language teaching according to contexts. There are core and peripheral beliefs suggested by Phipps and Borg (2009). Core belief is considered stable and influences behaviour more powerfully than peripheral belief. Core belief is acquired though experience while peripheral belief is acquired through theory (Phipps and Borg, 2009). Meanwhile, Rashidi and Moghadam (2015) suggested two types of teachers' belief as pedagogical and epistemological belief. Pedagocial belief is related to teaching, learning, students, subject matter, self as a teacher, and the role of a teacher (Calderhead, 1995) while epistemological belief is related to knowledge interpretation and cognitive monitoring (Acikalin, 2009).

Another suggestion by Hachfeld, Hahn, Schroeder, Anders, Stanat, and Kunter (2010) is that there are multicultural belief and egalitarian belief. Multicultural belief deals with different perspectives as the result of individuals' engagement in socio-cultural context. Teachers with multicultural belief apply this kind of belief by considering students' different cultures into teaching and learning practice including planning their lessons, choosing materials, and interacting with students in classroom. Meanwhile egalitarian belief focuses on equality in treating all people equally. In this case similarities and common traitss between students of different ethnic and cultural backgrounds are exposed regardless of their ethnic or cultural background. Instead of considering the students' cultural background, teachers with this belief treat them equally by exploring the various students' similarities.

Staub and Stern in TALIS (2009) mentioned two types of teacher's belief towards their students learning as direct transmission view and constructivist view. Teachers with direct transmission view believe that teacher is the center in the classroom. Communicating knowledge in a clear and structured way, explaining correct solutions, giving students clear and resolvable problems, and ensuring calm and concentration in the classroom are what a teacher should do in teaching and learning process. In contrast, teachers with constructivist view believes in students as the center of teaching and learning process. Students are not allowed to be passive recipients but are expected to be active participants in the process of acquiring knowledge. Teachers' job is to facilitate student inquiry, to give students the chance to develop solutions to problems on their own, and to allow students to play active role in instructional activities. In this case, the acquisition of specific knowledge is less exposed while the development of thinking and reasoning processes is greatly taken into account.

\section{ENGLISH TEACHERS' CULTURAL BACKGROUND AND THEIR TEACHING BELIEF}

Culture is an unseparable part of human life. It forms and is formed by human's way of thinking, behaviour, value, tradition, and even belief. Therefore as human, teachers cannot be separated from their cultural background. Even culture can take part in shaping English teachers' belief about English.

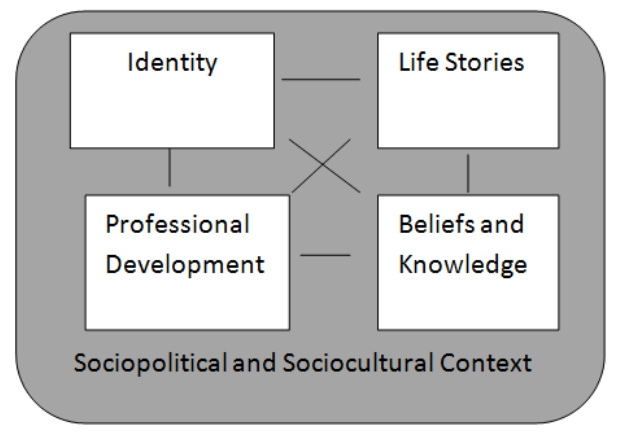

Figure 2. Teacher Profesional Development Johnston et al. (2005, p. 55)

Johnston et al. (2005, pp. 55-56) state that teachers' life stories, professional development, beliefs and knowledge even their identity can be known by considering their social, cultural, and political context in which they exist. This shows that cultural background has great influence in forming teacher's belief.

As mentioned in the previous section, cultural background which is considered to be discussed in this paper are way of thinking, behaviour, value, tradition, and belief in a society. Applying the cultural background into teaching and learning context, the aforementioned aspects are discussed in this section as teachers' previous knowledge, their transition from 
being students until being teachers, and their transaction with other components in teaching and learning process as suggested by Green and Mcintyre (2011, pp.13-16).

As way of thinking, teachers' previous knowledge about the subject matter is taken into account. Meanwhile, the transition from being students until being teachers which form teachers' behaviour and value will be discussed in detail. Finally, their transaction with other components in teaching and learning process as a result of tradition and belief are elaborated as the red line between cultural background and teachers' belief.

Teachers's previous knowledge about the subject matter deals with what the teachers know about English. According to Kujawa and Huske in Presseisen (1995) previous knowledge related with what is already known and makes sense of learning experiences. What teachers know about English consists of the components of English (the skills, the grammar, literature, linguistics) and their relation, and the relation of English with social context. Here, teachers' way of thinking which has been formed culturally takes part to form teachers' belief. As mentioned in the previous section, teachers in globalized area who see English as global language have greater effort to force students to use English compared to teachers in conventional area where English is not that necessary. English skills like speaking, reading, listening, and writing will be taken into main account by teachers in global area while grammar and vocabulary memorization will be the focus of teacher in conventional area.

Beside knowledge, teachers' experiences of studying English during their transition is also an important thing to take into account. The transition from being students until being teachers covers the process of teaching and learning in which the teachers involved before, the problem solving handled by their teachers before, and even the relation between them and their previous teachers. Green and Mcintyre (2011, p.11) claim that the teachers' perspective and favor on subject matter are formed by their previous teachers and lecturers' philosophies and preferences which were represented through the way they were taught during their transition. Here cultural behaviour affects the teachers' behaviour in the classroom.

In addition, teachers' transaction with other components in teaching and learning process cannot be ignored in discussing about cultural background and teachers' belief. The teachers' relation with their students must be similar to their relation with their teachers before and the habit of teacher-students relation in the area where the teachers teach. The habit which is shaped during their previous education and training before especially in relation with their previous teachers, must be implemented in their own class. Beside that, the habit of teaching which is formed in the area where the teachers live and teach must be implemented in their class. For example when the relation between teachers and their previous teacher were built in discipline and strict way and the teachers succeed in their education, they come to a belief that discipline is a good way to help the students to be success in studying. Therefore they implemented a discipline way in their classroom. Teachers can also implement a friendly and fun way of teaching in their classroom if they are influenced by the environment where such way of teaching is mostly implemented in the school.

In addition, the transition forms likeness or dislikeness about English which plays crucial role in teaching belief. Firstly, the transition creates the likeness and dislikeness of English in the teachers' (who were the students at that time) minds and may lead them to decide whether they would be English teachers or not. In a research dealing with teachers' motivation, Ornstein et al. (2011, p.3) state that 53 percent of the respondents decide to be teacher because they are inspired by their favourite teachers. Secondly, becoming English teachers for those who like English during their previous education, makes the teachers view English interesting and thus they enjoy teaching English. However sometimes becoming English teachers is not what dreamt by the teachers before because English teacher might be their additional choice when they enter 
universities. Unfortunately, it then become what they had to major because they were not passed the test for their main choice. This condition may become the cause of teaching students uninterestingly. Here cultural value takes part in influencing teachers' belief.

By considering the discussion before, cultural background and English teachers' belief can have both positive and negative red line. It can be positive when cultural background helps teacher to set belief which brings successful teaching and learning process. For example nonnative speaker English teachers who teach EFL can teach students based on students' needs. Since they are also nonnative speakers of English, they surely have experience of learning English as foreign language, and they know what is needed importantly in studying English. However it can be negative when the cultural background results an unsuccessful teaching and learning process since the belief does not help the teacher to build good relation with the students. For example an English teacher is from a very strict and discipline family. Therefore he implements strict and discipline way of teaching since he beliefs that being discipline can lead the students to succeed. Unfortunately, this way of teaching makes the students get nothing during the class because they are stressed of being strict and discipline.
Since teachers' belief is stable and is difficult to change, it is important for the teacher to not rely only on their belief in deciding what to do in the classroom, how to face the classroom challenges, and how to deal with the students. They need to pay attention to students' needs and the demand of English teaching development as well because the success of English teaching and learning process is determined by not only teachers but also students and other supporting language teaching aspects.

\section{CONCLUSION}

English teachers' cultural background which consists of way of thinking, behaviour, value, tradition and belief is considered as having relation to teachers' belief on language teaching. This aspects are interpreted into teacher's previous knowledge, their transition from being students until being teachers, and even their transaction with other components in teaching and learning process to show how cultural background has relation with teachers' belief.

The red line between cultural background and teachers' belief can be positif and negatif. Thus, teachers need to consider not only their belief but also students' needs and other supporting aspects in deciding what to do in the classroom, how to face the classroom challenges, and how to deal with the students.

\section{REFERENCES}

Acikalin, F. S. (2009). Teacher Beliefs and Practice In Science Education. Asia-Pacific Forum on Science Learning and Teaching, Volume 10, Issue 1, Article 12, p.1

Braine, G. (2010). Nonnative Speaker English Teacher-Research, Pedagogy, and Professional Growth. New York:Routlege-Taylor and Francis Group

Calderhead, J. (1995). Teachers: Beliefs and Knowledge. in Borg, M. Teachers' Belief. Key Concepts in ELT.

Carter, R. And Nunan, D. (2001). The Cambridge Guide to Teaching English to Speakers of Other Languages. Cambridge: Cambridge University Press.

Gilakjani, A.P and Sabouri, N.B. (2017). Teachers' Beliefs in English Language Teaching and Learning: A Review of the Literature. English Language Teaching; Vol. 10, No. 4

Green, A. (2011). Becoming A Reflective English Teacher. New York: Open University PressMcGrawHill.

Ha, P. L. (2008) Teaching English as an International Language-Identity, Resistance and Negotiation. Great Britain: Cromwell Press Ltd. 
Hachfeld, A. Hahn, A. Schroeder, S. Anders, Y. Stanat, P. Kunter, M. 2011. Assessing teachers' multicultural and egalitarian beliefs: The Teacher Cultural Beliefs Scale. Teaching and Teacher Education 27.

Kisaka, J. 2015. Cultural Factors Hindering Mastery Of English Language In Primary And Secondary Schools: A Case Of Kilifi County, Kenya. British Journal of Education Vol.3, No.2, pp. 38-44

Naser Rashidi, N. and Moghadam, M. (2015). The Discrepancy between Teachers' Belief and Practice, from the Sociocultural Perspective. Studies in English Language Teaching. Vol. 3, No. 3

Ornstein, et al. (2011) Foundation of Education. Wadsworth: Cengange Learning

Phipps, S. and Borg, S. (2009). Exploring tensions between teachers' grammar teaching beliefs and practices. Sytem, No. 37.pp. 380-390.

Presseisen, B. Z. (1995). Critical Issue: Building on Prior Knowledge and Meaningful Student Contexts/Cultures North Central Regional Educational Laboratory

Richards, J.C and Renandya, W.A. (2002). Methodology in Language Teaching- An Anthology of Current Practice. New York: Cambridge University Press

TALIS, (2009). Creating Effective Teaching and Learning Environments: First Results from TALIS. OECD.

Tedick, D.J. (2005) Second Language Teacher Education-International Perspectives. Mahwah, New Jersey, London: Lawrence Erlbaum Associates, Publishers.

$\mathrm{Xu}$, Li. (2012). The Role of Teachers' Beliefs in the Language Teaching-learning Process. Theory and Practice in Language Studies, Vol. 2, No. 7, pp. 1397-1402. 